\title{
1986 - 2001: IDEAIS E SONHOS CONCRETIZADOS EM 15 ANOS DE LUTAS, TRABALHOS E CONQUISTAS DAABEN - REGIONAL TIAJUBA
}

\author{
1986 - 2001: THE CONCRETIZATION OF IDEALS AND DREAMS IN \\ FIFTEEN YEARS OF STRUGGLE, WORK AND ACHIEVEMENTS OF THE \\ BRAZILIAN ASSOCIATION OF NURSING IN THE CITY OF ITAJUBÁ \\ 1986 - 2001: IDEALES Y SUEÑOS CONCRETIZADOS EN 15 AÑOS DE \\ LUCHAS, TRABAJOS Y CONQUISTAS DE LAABEn - REGIONAL ITAJUBÁ
}

\author{
Aldaiza Antunes Ferreira Fortes ${ }^{7}$ \\ Ana Maria Nassar Cintra Soane" \\ Cristiane Giffoni Braga ${ }^{3}$ \\ Maria Ligia Mohallem Carneiro
}

RESUMO: O artigo relata à luz de momentos vivenciados em 15 anos, a trajetória da ABEn -Regional Itajubá, desde sua criação até os dias atuais. Mostra os esforços empreendidos e o sucesso obtido que cresceu e fortaleceu a Enfermagem na Região Sul Mineira.

PALAVRAS-CHAVE: ABEn, organização de enfermagem, história

\section{INTRODUÇÃO}

AAssociação Brasileira de Enfermagem - ABEn - fundada em 1926, é a primeira entidade de classe de enfermagem no Brasil. Atualmente é composta por 24 Seções e 26 Regionais com associados em todo o pais, empenhados em concretizar uma proposta de trabalho que tem como finalidade a promoção e viabilização do desenvolvimento técnico-científico, profissional e político da enfermagem brasileira.

No ano de 2001, quando a ABEn Regional Itajubá completa 15 anos de sua existência, se faz imprescindivel um resgate de sua história, seus sonhos, suas lutas conquistas em prol do crescimento da profissão, como também afirmação junto às demais da área da saúde,

Desde 1998, assumir esta diretoria está sendo para nós um desafio. Desafio sim, pois

'Enfermeira. Docente da Escola de Enfermagem Wenceslau Braz. Mestranda em Enfermagem pela Universidade Federal de Minas Gerais- UFMG. $1^{a}$ Tesoureira da ABEn - Regional Itajubá - MG. Gestão 98/01.

${ }^{2}$ Enfermeira. Docente da Escola de Enfermagem Wences/au Braz, Escola de Enfermagem da Universidade de Pouso Alegre -UNIPA. Mestranda em Enfermagem pela Universidade Federal de Minas Gerais -UFMG. 2a Tesoureira da ABEn - Regional Itajubá- MG. Gestão 98/01.

${ }^{3}$ Enfermeira. Docente da Escola de Enfermagem Wences/au Braz. Mestre em Enfermagem pela Escola de Enfermagem da Universidade de São Paulo - EEUSP. Doutoranda em Enfermagem na Escola de Enfermagem da Universidade de São Paulo -EEUSP. Presidente da ABEn - Regional Itajubá- MG. Gestão 98/01.

${ }^{4}$ Enfermeira,Profa. Adjunta / do Departamento Materno-Infantil e saúde Pública da Escola de Enfermagem da Universidade Federal de Minas Gerais-UFMG. Doutora em Enfermagem pela Escola de Enfermagem da Universidade de São Paulo -EEUSP. 
não é fácil conscientizar as pessoas da importância de uma associação, que nasceu junto com a enfermagem brasileira, e ao mesmo tempo satisfazer a todos. Sabendo-se que a enfermagem faz a história no seu cotidiano, e nós, enquanto enfermeiras, fazendo parte dela, decidimos relatar esta experiência com o intuito de divulgar a trajetória de atuação de nossas antecessoras nesta Regional. Portanto, ao conhecer esta Entidade, você simultaneamente estará compreendendo uma pequena parcela da própria história da Enfermagem Brasileira.

\section{RESGATANDO A CAMINHADA DA “ABEn - REGIONAL ITAJUBA”...}

A idéia da criação de um Distrito da Associação Brasileira de Enfermagem (ABEn) em Itajubá, surgiu do ensejo da enfermeira Lucyla Junqueira Carneiro. Apoiada e incentivada a idéia, iniciou-se no $2^{\circ}$ semestre de 1984 um intercâmbio de informações com a então Presidente da ABEn - Seção Minas Gerais, Enfermeira Dulce de Castro Mendes.

Em 20 de janeiro de 1985, houve a visita da Presidente da ABEn - Seção Minas Gerais na $1^{\text {a }}$ reunião com um grupo de enfermeiras professoras, enfermeiras e técnicas de enfermagem das instituições de Itajubá, totalizando 17 pessoas. O principal objetivo era estudar a possibilidade da criação de um Distrito em Itajubá.

A referida presidente da ABEn - Seção Minas Gerais fez uma breve explanação das vantagens e da exigência para a criação de Distrito, a saber como vantagens: levar mais enfermeiros a participar e trabalhar pela enfermagem, maior articulação com as técnicas e auxiliares de enfermagem e descentralizar para caminhar. Como exigência, assinatura de 40 pessoas, entre enfermeiros e técnicos.

Foi sugerida nesta mesma reunião, a formação de uma comissão para que a idéia da criação de um Distrito fosse levada em frente. A Comissão formada constou dos seguintes elementos: Lucyla Junqueira Carneiro, Maria Aparecida Pereira, Querubina Pivoto de Almeida, Ruth Maria Rezende Bustamante, Magaly de Abreu, Kátia Maria Mont'alvão Siqueira, Maria de Lourdes Cardoso Miranda, Dalva Maria Lemos Beraldo e Ana Maria Bueno.

Em 25 de março de 1985 ocorreu a $2^{\mathrm{a}}$ reunião com a finalidade especial de compor as chapas para concorrerem à eleição da diretoria provisória do Distrito de Itajubá, após a aprovação da criação do referido Distrito conforme Ata da sessão realizada no dia 25 de março de 1985 (ASSOCIAÇÃO BRASILEIRA DE ENFERMAGEM, 1995b). Foi organizada chapa única com os seguintes elementos: Zilda de Castro Coelho (Presidente), Maria Leonor Amaral ( $1^{\circ}$ Vice Presidente), Magaly de Abreu ( $2^{\text {a } V i c e ~-P r e s i d e n t e), ~ Q u e r u b i n a ~ P i v o t o ~ d e ~ A l m e i d a ~(1 ~} 1^{\text {a Secretária) }}$ , Kátia Maria Mont'alvão Siqueira ( $2^{\mathrm{a}}$ secretária), Elza Lopes Rocha ( $1^{\mathrm{a}}$ tesoureira), Maria Aparecida Rodrigues ( $2^{a}$ tesoureira); coordenadora da Comissão do Serviço de Enfermagem Maria Marly Simões; coordenadora da comissão de atividades cientificas Izilda Aparecida de Souza. Conselho fiscal: Inácia Maria Rezende Bustamante, Ruth Rezende Bustamante e Maria Aparecida Alves.

Como a maioria das enfermeiras presentes não tinha habilitação para candidatar-se a cargos, por falta de carência do tempo de filiação à $A B E n$, e não se acharem algumas das demais em condições de aceitar cargos, a presidente da ABEn - MG, Dulce de Castro Mendes, foi consultada e concordou que fosse aberta uma exceção, que dependeria da aprovação e decisão final da assessoria jurídica da mesma associação. Foi aprovado pela assessoria jurídica da ABEn - Seção Minas Gerais que pelo menos o cargo de presidente atendesse às exigências do estatuto vigente. Com isto, ficou decidido, com a aprovação de todos os presentes, a indicação da Prof ${ }^{a}$ Enf. Maria Lígia Mohallem Carneiro para substituir a Enfa Zilda de Castro Coelho, na presidência da chapa, e esta ficaria como Coordenadora da Comissão de Publicações e Divulgação.

Houve o processo eleitoral em que se deu a eleição, no dia 10 de setembro de 1986, da $1^{\text {a }}$ Diretoria da ABEn - Distrito Itajubá, que foi empossada dia 20 do mesmo mês e ano, sendo constituida pelos seguintes elementos: Presidente: Maria Ligia Mohallem Carneiro ${ }^{5}$, Vice- 
Presidente: Maria Leonor Amaral, $1^{\text {a }}$ Secretária: Querubina Pivoto de Almeida, $2^{\text {a Secretária: }}$ Terezinha de Faria, $1^{\text {a }}$ Tesoureira: Elza Lopes Rocha, $2^{\mathrm{a}}$ Tesoureira: José Barbosa dos Santos. Conselho Fiscal: Irmã Magaly de Abreu, Maria Aparecida Alves, Ruth Maria Rezende Bustamante.

Esta diretoria foi eleita para o triênio 86/89. Neste dia como marco comemorativo, organizou-se um seminário em celebração aos 60 anos da ABEn Nacional e a Enfermagem Brasileira, para debater assuntos de interesse da classe, cujos temas foram: ABEn 1926-1986; Divisão Social do Trabalho e a Enfermagem , Saúde Dialética do Pensar e Fazer; o Saber da Enfermagem e sua Dimensão Prática.

Neste cenário, a ABEn Regional Itajubá foi iniciando a busca pela concretude da meta da Entidade, através da realização da Jornada Mineira e Semanas de Enfermagem. Estes eventos, de relevância, tornaram-se desafios não só para a projeção desta Regional, como também no despertar dos profissionais de enfermagem da Região de Minas Gerais para o compromisso e importância de participar nesta Entidade de Classe.

Tal fato é corroborado por Silva (1998, p.28) ao afirmar que: "AABEn não pode traduzir o pensamento de uma só pessoa, mas a discussão reflexiva de idéias que possibilitem a criação de um espaço para viabilizar o debate de temas atuais e polêmicos, que leve ao avanço no processo de crescimento da profissão como co-protagonista da melhoria dos serviços e ações de saúde oferecidos à população e, por fim, que responda também aos interesses, naturalmente heterogêneos, dos nossos associados."

Em 06 de novembro de 1989 foi empossada a $2^{\mathrm{a}}$ Diretoria para o triênio 89/92, agora denominada ABEn - Regional Itajubá, sendo composta pelos seguintes membros: Presidente: Waldere Fabri Pereira Ribeiro, Vice-Presidente: Ana Maria Nassar Cintra Soane, $1^{\text {a }}$ Secretária: Terezinha de Faria, $2^{\text {a }}$ Secretária: Márcia Pereira da Silva, $1^{\text {a }}$ Tesoureira: Mariângela Gomes Paixão, $2^{\text {a }}$ Tesoureira: Maria Nazaré Goulart Ferraz, Conselho Fiscal: Silvana Maria Vilas Boas Pappi, Lucia Renata Rodrigues da Silva e Ethel Duarte Coutinho, Comissão Permanente de Divulgações e Publicações: Heloisa Helena de Almeida Duarte.

Esta gestão destacou-se por enfatizar em seus eventos cientificos temas relacionados e integrados à enfermagem, com profissionais de diversas áreas como: fisioterapeutas, pedagogos, fitoterapeutas, médicos, vigilantes sanitários, obstetrizes.

Observa-se nesta gestão que a ABEn - Regional Itajubá fortaleceu o trabalho iniciado, compartilhando com outros profissionais o conhecimento de enfermagem. Tal atitude denota uma alternativa que permitiu um "pensar coletivo".

"É necessário que as ações ocorram na direção de se construir novas formas de se lidar com o conhecimento, o que inclui, de modo marcante, o espaço transdisciplinar e não tradicional para a produção e incorporação do saber". (Carneiro et al., 2000, p. 77)

No decorrer do ano de 1990 ocorreu a evasão de 05 elementos da diretoria, sem a devida comunicação, ficando esta constituida por: Waldere Fabri Pereira Ribeiro (Presidente), Ana Maria Nassar Cintra Soane (Vice-Presidente), Terezinha de Faria ( $1^{\text {a }}$ Secretária), Mariângela Gomes Paixão ( $1^{\text {a }}$ Tesoureira) e Heloisa Helena de Almeida Duarte (coordenadora da Comissão Permanente de Divulgação e Publicações).

A posse da $3^{a}$ Diretoria para o triênio 92/95 se deu no dia 23 de outubro de 1992, sendo constituida pelos seguintes elementos: Presidente: Júlia de Fátima Umbelino, Vice-Presidente: Aldaiza Ferreira Antunes Fortes, $1^{\text {a }}$ Secretária: Odinéa Martins Riêra Fidélis, $2^{\mathrm{a}}$ Secretária: Benedita Lúcia Alkmin, $1^{\text {a }}$ Tesoureira: Heloisa Helena de Almeida Duarte e $2^{\text {a }}$ Tesoureira: Maria Regina Leite Garrido Silva.

Em 18 de abril de 1994 foram empossados para o biênio 94/95 os seguintes membros: Inácia Maria Rezende Bustamante (Vice-Presidente); Cristiane Giffoni Braga (1ª Tesoureira) e

${ }_{5}^{5}$ Por estar à época afastada para cursar mestrado na EEAN-UFRJ, assumiu a Diretoria da ABEn-Regional da ABEn, a Vice-Presidente. 
José Barbosa dos Santos ( $2^{\circ}$ Tesoureiro). Tal fato ocorreu decorrente da renúncia de cargos, por motivos particulares, da Presidente e Tesoureiros.

Vale ressaltar a ascensão de cargos da Vice-presidente eleita no triênio 92/95, Aldaiza Ferreira Antunes Fortes, para o cargo de Presidente no biênio 94/95.

Dando continuidade ao trabalho da Regional Itajubá, os membros da atual Diretoria promoveram cursos, semanas de enfermagem e mesas redondas visando solidificar a valorização e atuação dos profissionais de saúde da região, através de relatos de experiências nas áreas hospitalar e de saúde coletiva. Esta iniciativa fortaleceu os laços de intercâmbio entre docentes e assistenciais da Região.

Neste sentido, percebe-se que "docentes e enfermeiros assistenciais devem envidar esforços e compartilharem da mesma filosofia que norteará o ensino e a assistência multiplicando a amplitude cognitiva e o potencial criativo; o que favorecerá a liberdade de pensamento e gerenciamento da complexidade ensino-assistência na melhoria da assistência prestada à população." (Gerges, 1995, p.236).

Para o triênio 95/98 assumiram a $4^{\text {a }}$ Diretoria os seguintes profissionais: Presidente: Vera Lúcia de Paula; Secretária Geral: Rivadávia dos Santos G. de Castro; $1^{\text {a }}$ Secretária: Ana Márcia Gomes Freires; $1^{a}$ Tesoureira: Maria Cecilia Corrêa Tótora e $2^{a}$ Tesoureira: Christiane Salomon Bezerra Calláu.

Em reunião realizada no dia 04 de maio de 1996 decidiu-se transferir a sede da ABEn Regional itajubá, situada nas dependências da EEWB, para a Policlínica do Sistema Único de Saúde de Itajubá, como intuito de facilitar o trabalho da equipe, pois a maioria de seus elementos pertenciam a esta instituição de saúde.

As tesoureiras desta gestão solicitaram, em agosto de 1996, afastamento dos respectivos cargos. Diante disto, foi convocada uma Assembléia Geral para apresentação de novas candidatas aos cargos de tesoureiros e $2^{\mathrm{a}}$ secretária, pois esta não comparecia às reuniões realizadas. Foram ocupados os cargos de $2^{a}$ tesoureira, $2^{a}$ secretária e $1^{a}$ tesoureira por Maria Cecilia Corrêa Tótora, Maria Aparecida Pinto Soares e Danielle Aparecida Nazário Santos.

Esta diretoria além da diversidade de eventos contemplando várias áreas da profissão enfermagem, procurando solidificá-la em sua dimensão técnico-cientifica, procurou fazer emergir a dimensão cultural da enfermagem, através da música e de confraternização comos associados. Em 17 de novembro de 1998 foi empossada a $5^{\text {a }}$ Diretoria para o triênio 98/01 tendo como Presidente: Cristiane Giffoni Braga, Secretária Geral: Terezinha de Faria, $1^{\text {a }}$ Secretária: Valdinéa Luiz, $1^{\text {a }}$ Tesoureira: Aldaiza Ferreira Antunes Fortes, $2^{\text {a }}$ Tesoureira: Ana Maria Nassar Cintra Soane.

Pelo novo Estatuto (ASSOCIAÇÃO BRASILEIRA DE ENFERMAGEM, 1985a) aprovado em Assembléia Nacional de Delegados da ABEn, em outubro de 1994, os cargos de VicePresidente e $2^{\text {a }}$ Secretária foram extintos, surgindo o cargo de secretária geral; constituindo assim em 05 elementos a Diretoria.

No dia 18 de novembro de 1998 a Sede da ABEn Regional Itajubá retornou para as dependência da EEWB, uma vez que todos os membros desta diretoria são docentes desta Instituição.

Entre os eventos promovidos na atual gestão, destacou-se pelo contexto sócio-político da enfermagem brasileira, reflexões bioéticas que norteiam o agir da enfermagem diante do cliente/paciente.

Na ótica de Germano, Brito e Teodósio (1998, p.375) "a qualidade do desempenho profissional passa necessariamente pela questão da competência, cuja dimensão técnica e politica muitas vezes aparece dicotomizada no discurso e na prática dos profissionais de enfermagem. A superação dessa dicotomia se dá exatamente através da dimensão ética que tem a propriedade de exercer a mediação entre ambas."

Nestes 15 anos a ABEn Regional Itajubá contou com 910 associados. Devemos lembrar 
que a participação é de extrema importância, sendo fundamental para trilharmos novos caminhos, repensarmos a essência de nossa profissão e garantirmos a visibilidade de nossa identidade.

Vale $(1998$, p.438) ressalta que "a categoria se encontra comprometida com a valorização e projeção da enfermagem como prática social, entendida no âmbito do processo de construção coletiva de uma sociedade, ainda desigual, em permanente ciclo de contradições mas que, na práxis da dialética cotidiana almeja minimizar as injustiças sociais."

\section{CONSIDERAÇŐES FINAIS}

Ao resgatarmos os 15 anos da existência desta Regional, estamos conscientes da responsabilidade assumida, e que os sonhos, as lutas e conquistas obtidas nos dão força para darmos seguimento na concretização de nossos ideais. Temos certeza que estamos todos lutando sempre e, cada vez mais, para fortalecer esta Entidade de Classe.

Não há presente sem passado e nem o "agora" sem a inexorável perspectiva do futuro.

Finalizando, citamos Vale (1998, p.438) que, pautada em Sartre afirma que "o sonho é real à medida que propicia ao sonhador a concretização do onírico"... "Portanto se faz necessário despertar, mas continuar sonhando".

ABSTRACT: The present article reports the trajectory of a regional branch of the Brazilian Association of Nursing (ABEn) in Itajubá. It shows the development of this association since its inception until the present days. The study also depicts how the efforts invested and the success obtained helped on the development and strengthening of the nursing work in the south region of Minas Gerais.

KEYWORDS: ABEn, ABEn-Itajubá, history, nursing

RESUMEN: El artículo relata, a la luz de los momentos vividos en 15 años, la trayectoria de la ABEn Regional de Itajubá, desde su creación hasta los dias actuales. Muestra los esfuerzos emprendidos y el éxito obtenido que ha crecido y ha fortalecido a la Enfermeria en la Región Sur de Minas.

PALABRAS CLAVE: ABEn, ABEn-Itajubá, historia, enfermeria

\section{REFERÊNCIAS BIBLIOGRÁFICAS}

ASSOCIAÇÃO BRASILEIRA DE ENFERMAGEM. Estatuto da Associação Brasileira de Enfermagem. Brasilia, 1985 a. p. 9.

ASSOCIAÇÃO BRASILEIRA DE ENFERMAGEM. Regional Itajubá. Livro de Atas. Itajubá, 1985 b.

CARNEIRO, M. L. M. et al. Construindo caminhos para a troca de saberes: produção e incorporação de tecnologias apropriadas. Rev. Bras. Enf., Brasilia. v. 53, p.77-9, dez. 2000 . Número especial.

GERGES, M. C. Interpretação docente-assistencial ou... entre o departamento de enfermagem e o Hospital Universitário da Universidade Federal de Santa Catarina. Rev. Texto \& Contexto, Florianópolis, v. 4, p.230-37, 1995. Número especial.

GERMANO, R. M.; BRITO, R. S. ; TEODÓSIO, S. S. O comportamento ético dos enfermeiros dos hospitais universitário. Rev. Bras. Enf., Brasília, v.51, n.3, p.369-78, jul/set.1998.

SILVA, A. L. C. Discurso da Presidente da ABEn -Bahia e da comissão executiva. In: CONGRESSO BRASILEIRO DE ENFERMAGEM, 50., 1998, Salvador. Anais... Salvador: ABEn, 1998. p. 28.

VALE, E. G. Discurso da Presidente da ABEn Nacional. Gestão1998-2001. In: CONGRESSO BRASILEIRO DE ENFERMAGEM, 50., 1998, Salvador. Anais... Salvador: ABEn, 1998. p.438 